\title{
Pharmacogenetics and Predictive Testing of Drug Hypersensitivity Reactions
}

\author{
Ruwen Böhm and Ingolf Cascorbi* \\ Institute of Experimental and Clinical Pharmacology, University Hospital Schleswig-Holstein, Kiel, Germany
}

Adverse drug reactions adverse drug reaction (ADR) occur in approximately $17 \%$ of patients. Avoiding ADR is thus mandatory from both an ethical and an economic point of view. Whereas, pharmacogenetics changes of the pharmacokinetics may contribute to the explanation of some type A reactions, strong relationships of genetic markers has also been shown for drug hypersensitivity belonging to type $B$ reactions. We present the classifications of ADR, discuss genetic influences and focus on delayed-onset hypersensitivity reactions, i.e., drug-induced liver injury, drug-induced agranulocytosis, and severe cutaneous ADR. A guidance how to read and interpret the contingency table is provided as well as an algorithm whether and how a test for a pharmacogenetic biomarker should be conducted.

\section{OPEN ACCESS}

Edited by:

José A. G. Agúndez,

University of Extremadura, Spain

Reviewed by:

Klaus Golka

Leibniz Research Centre for Working Environment and Human Factors,

Germany

José Antonio Cornejo-García, Instituto de Investigación Biomédica de Málaga, Spain

${ }^{*}$ Correspondence: Ingolf Cascorbi cascorbi@pharmakologie.uni-kiel.de

Specialty section: This article was submitted to Pharmacogenetics and Pharmacogenomics, a section of the journal Frontiers in Pharmacology

Received: 13 July 2016 Accepted: 07 October 2016 Published: 21 October 2016

Citation: Böhm R and Cascorbi I (2016) Pharmacogenetics and Predictive

Testing of Drug Hypersensitivity Reactions. Front. Pharmacol. 7:396. doi: 10.3389/fphar.2016.00396
Keywords: adverse drug reactions (ADRs), drug hypersensitivity reactions, drug-induced agranulocytosis (DIA), drug-induced liver injury (DILI), drug-induced severe cutaneous adverse reactions (SCARs)

\section{INTRODUCTION}

Apart from their intended principal therapeutic use, drugs action is always related to the risk of ADRs. ADR are an important cause of morbidity and mortality. It is estimated that $3.6 \%$ of all hospital admissions are due to an ADR and that $17 \%$ of all in-patients develop ADR, an estimated $0.5 \%$ of all ADR is lethal (Bouvy et al., 2015). The mean costs of a single ADR event in Germany has been calculated as 2,743 EUR (Meier et al., 2015). An U.S. American study reports costs from 1,439 USD to 13,462 USD (Alagoz et al., 2016). Avoiding ADR is thus mandatory from both an ethical and an economic point of view. We present the classifications of ADR, discuss genetic influences with focus on delayed-onset hypersensitivity reactions, i.e., DILI, DIA and SCAR, and present an algorithm when and how to test for relevant pharmacogenomic biomarkers.

\section{Taxonomy of Adverse Drug Reactions (ADRs)}

Adverse drug reaction are divided into types A and B ADR (Figure 1). Type A ADR, the socalled "pharmacological ADR," are caused (i) by a change of dosage and/or pharmacokinetics and consequently of its pharmaco- or toxicodynamic action or (ii) solely by a change in the target

Abbreviations: ACEi, angiotensin-converting-enzyme-inhibitor; ADR, adverse drug reaction; AERD, aspirin-exacerbated respiratory disease; AIU, aspirin-induced urticaria; ASA, acetylsalicylic acid; CPIC, Clinical Pharmacogenetics Implementation Consortium; CysLT, cysteinyl leukotriene; DIA, drug-induced agranulocytosis; DILI, drug-induced liver injury; DRESSs, drug rash with eosinophilia and systemic symptoms; HLA, human leukocyte antigen; LTs, leukotrienes; $\mathrm{MCH}$, major histocompatibility complex; NAT, arylamine $N$-acetyltransferase; NNS, number needed to screen; NPV, negative predictive value; NSAID, non-steroidal anti-inflammatory drug; PAF, platelet-activating factor; PGs, prostaglandines; PPV, positive predictive value; SCAR, severe cutaneous ADR; SJS, Steven Johnson's syndrome; TEN, toxic epidermal necrolysis; USAN, U.S. Adopted (Drug) Name; USAN, aspirin. 


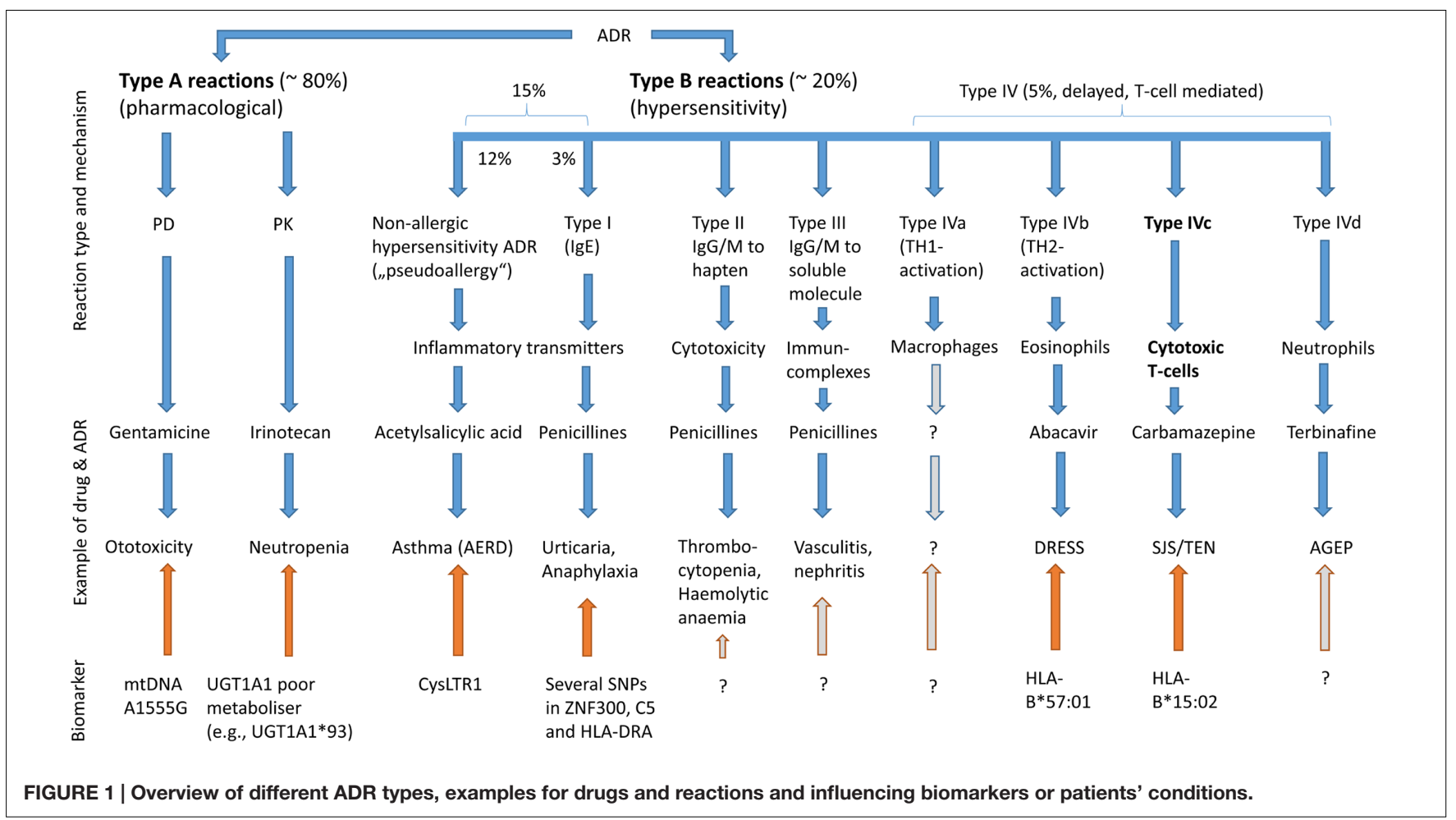

structure leading to different affinity of the drug to the target and/or a different agonist-directed trafficking at the (target-) receptor. In contrast, type $\mathrm{B} A \mathrm{ADR}$, drug hypersensitivity $\mathrm{ADR}$, are caused by allergic or non-allergic mechanisms involving the immune system and/or mediators such as histamine (Figure 2). Type A were estimated to account for approximately $80 \%$ of ADR occurring in clinical practice (Borda et al., 1968). However, this figure has undoubtedly changed over the last 50 years due to differences in drug prescriptions, pharmacovigilance activities and a better understanding and thus demarcation of type B ADR. 34 years later, maybe owing to these advances in medicine, type A were reported to account for $91 \%$ of all ADR (Mjorndal et al., 2002).

In the past, it was postulated that type A ADR are usually a feature of the drug property and thus predictable, while type $B$ ADR are strongly dependent on the genetic features of the host. Pharmacogenetic polymorphisms are now known to aggravate certain type A ADR (cf. descriptions of AERD and red-mansyndrome below). Type B ADR appeared to be non-predictable and dose-independent. However, dose-dependency has been shown for some hypersensitivity reactions (Rive et al., 2013). Rising knowledge of genetic polymorphisms of the immune system have helped to predict at least some type B ADR by applying genotyping (Rive et al., 2013).

\section{Drug Hypersensitivity Reactions (type B ADR, Idiosyncrasy)}

Depending on the mechanism of activation of the immune systems, most type B ADR ( 75\%) can be classified as either nonallergic hypersensitivity ADR (formerly called "pseudoallergic"), i.e., direct effect on mast cells causing histamine release, or as type I reaction according to Gell and Coombs, i.e., IgE-mediated histamine release. Type IV reactions, i.e., T-cell-mediated delayed hypersensitivity reactions, are less common ( $\sim 25 \%)$. Types II and III reactions are uncommon among drug hypersensitivity reactions.

Besides these immune reactions types $\mathrm{I}$ to $\mathrm{IV}$, a direct pharmacologic action on immune receptors ("p-i concept") of T-cells without prior presentation of the drug via MHCs (coded by HLA) has been proposed (Posadas and Pichler, 2007). Finally, some drugs are thought to alter the functioning of the immune system, e.g., alpha-methyldopa can induce the production of drug-independent autoimmune antibodies (Pierce and Nester, 2011), and statins potentiate the shifting of T-helper 1 to T-helper 2 immune responses (Suchak et al., 2007).

\section{Examples, Clinical Manifestation, and Pharmacogenetics}

While type A ADR are usually a feature of the drug, drug hypersensitivity reactions are strongly dependent on the genetic features of the host. However, pharmacogenetic markers have been described for both types of ADR.

\section{Type A ADR}

Type A ADR depend on the toxico- or pharmacodynamic action of the drug and are thus diverse. E.g., aminoglycosides are ototoxic. However, this ototoxicity can be greatly enhanced by a polymorphism in the mitochondrial DNA coding for a 12S-ribosome vital for mitochondrial protein biosynthesis resulting in complete deafness during 


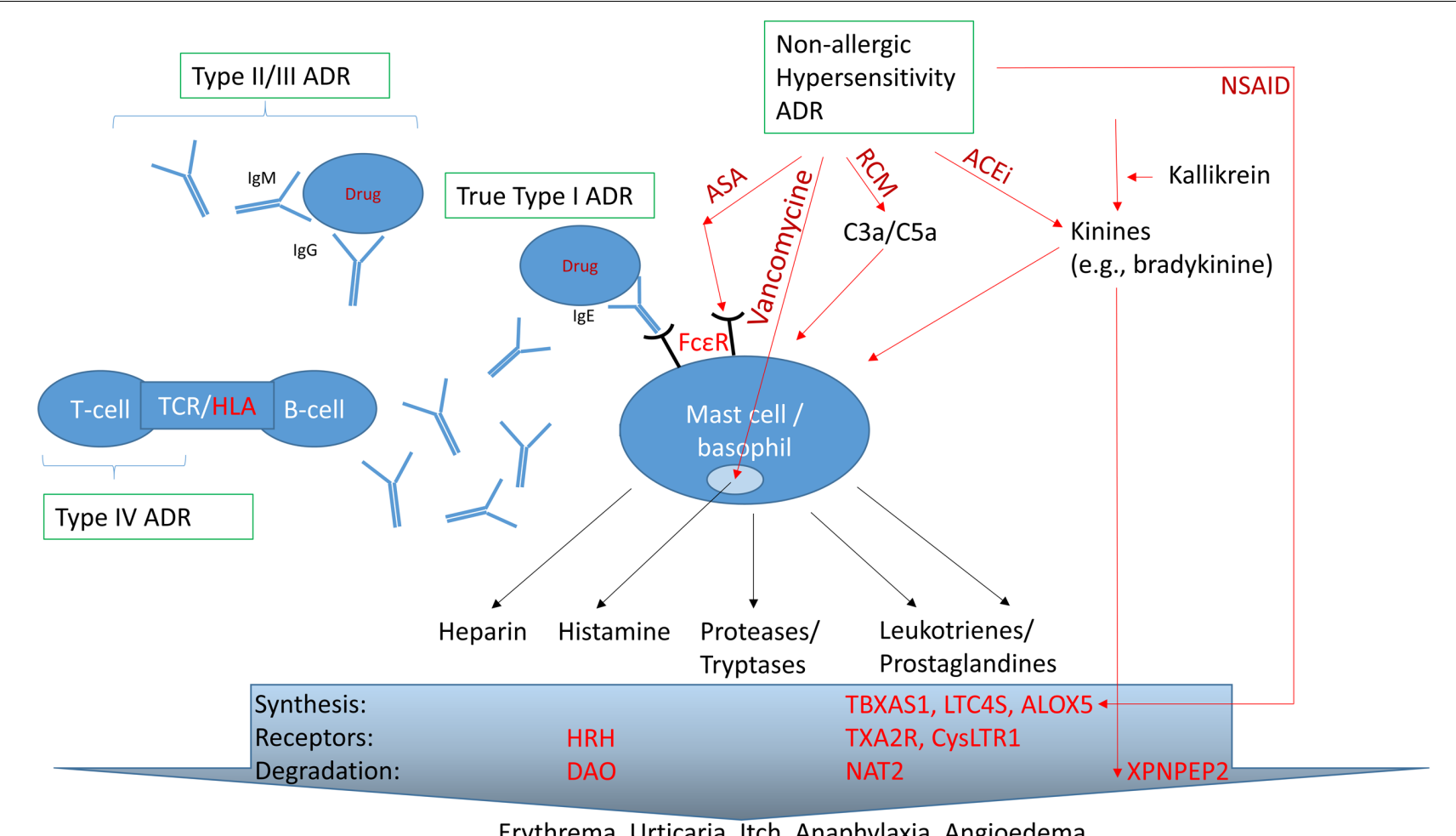

FIGURE 2 | Stimuli for degranulation of mast cells and basophils and interplay/overlap with type II-IV reactions. Beside the canonical IgE-mediated true allergic pathway, activation of the complement system and the direct interaction with IgE-receptor can lead to degranulation. Changes in the the metabolism and signaling of various arachidonic acid-derivatives, e.g., cysteinyl leukotrienes, or in the histaminergic system, as well as changes to the kallikrein-kinine-system are believed to aggravate any reactions. Light red: proteins/genes involved in hypersensitivity with known genetic associations; Dark red: example of drugs leading to primarily non-allergic hypersensitivity ADR. ACEi, angiotensin-converting-enzyme inhibitor; ALOX5, 5'-lipoxygenase; ASA, acetylsalicylic acid (USAN: aspirin); $\mathrm{C} 3 \mathrm{a} / \mathrm{C} 5 \mathrm{a}$, activated components 3 and 5 of the complement system; DAO, diaminooxidase; FCER, IgE-receptor; HLA, human leukocyte antigen; HRH, histamine receptor; LTC4S, cysteinyl leukotriene synthetase; NAT, N-acetyl transferase; NSAID, non-steroidal anti-inflammatory drugs; RCM, radio contrast media; TBXAS1, thromboxane synthetase; TCR, T-cell receptor; TXA2R, thromboxane receptor; XPNPEP2, aminopeptidase P.

aminoglycoside treatment (Estivill et al., 1998; Usami et al., 1998). Varying activities of drug metabolizing enzymes are the main cause of type A ADR. Classic examples for such pharmacokinetic variants is the poormetabolizer phenotype of the drug metabolizing enzyme UDP-glucuronosyl-transferase (UGT) $1 \mathrm{~A} 1$ which results in increased risk of neuropenia during high dose irinotecane therapy (Innocenti et al., 2009) or of cytochrome P450 2D6 causing an elevated risk of extrapyramidal symptoms while treatment with the neuroleptic haloperidol (Brockmoller et al., 2002).

\section{Immediate Reactions: Type I and Non-allergic Hypersensitivity ADR}

Mast cells and basophils can be stimulated to release inflammatory agents like histamine, heparin, leukotrienes, prostaglandins, cytokines, proteases, and PAF. If the stimulus derives from an IgE-antigen-complex it is considered a true type I allergic reaction. However, non-IgE-mediated responses are common and comprise approximately $77 \%$ of all reactions of this type (Demoly et al., 1999). For some drugs, both mechanisms apply (Canto et al., 2009).
After degranulation of mast cells and basophils, the resulting type I or non-allergic hypersensivitiy ADR mainly manifest in the skin as itch, urticaria, and erythema due to the proinflammatory substances released. Acute severe reactions, called anaphylaxia, involve the cardio-vascular system and the airways, i.e., swelling and edema of pharynx, larynx and bronchi with possible subsequent asphyxia. Anaphylaxia is seen more frequently with immediate hypersensitivity reactions than other types.

\section{Non-allergic hypersensitivity ADR ("pseudoallergy")}

There are several pathways for non-IgE-mediated mast cell/basophil degranulation (Figure 2).

Non-steroidal anti-inflammatory drug are very commonly used drugs that are frequently involved in hypersensitivity $\mathrm{ADR}$ in some individuals. They are reported to be the leading cause of hypersensitivity ADR (Dona et al., 2012). ASA, USAN or NSAID-exacerbated respiratory disease (AERD or NERD, respectively) and ASA-induced urticarial (AIU) were known to affect primarily individuals with allergic rhinitis and polyposis nasi after application of an NSAID. This phenotype is also commonly referred to as Samter's triad. The last decades shed 
light on various genetic markers associated with AERD/AIU, e.g., DAO (Agundez et al., 2012) and histamine-receptors (Ayuso et al., 2013). Other markers like IgE-receptors ( $F c \varepsilon R)$ and alterations in synthases, receptors and degrading enzymes of CysLT and thromboxanes are nicely reviewed by (Park et al., 2013; Gomez et al., 2015). The phenotype "nasal polyposis" is associated with certain HLA genotypes (Molnar-Gabor et al., 2000).

However, predictive testing for AERD/AIU appears to date not feasible due to the multitude of possible biomarkers and their relatively weak associations: E.g., recalculating the frequency data on CysLTR1 haplotypes and AERD (Kim et al., 2006) suggests that at least approximately 300 patients need to be genetically tested to avoid one incident. Cf. below (see section 'The Output') for more showcase calculations and points to consider for predictive testing.

Brisk displacement of histamine from mast cells/basophils can clinically present as red-man-syndrome which is seen after rapid intravenous exposure to a variety of drugs, e.g., vancomycine, ciprofloxacine, and amphotericine B. The red-man-syndrome after application of vancomycine was linked to a missense polymorphism in the diaminooxidase (DAO) gene at c.995C > A (Myers et al., 2012). DAO is needed for efficient degradation of histamine. Defects thus cause or aggravate histamine-dependent ADR.

Mastocytosis is a pathological condition leading to large amounts of histamine being released to a variety of stimuli, including commonly used drugs like NSAIDs. While mastocytosis is poorly understood, an association with a missense variant in c-Kit gene (c.2468A $>\mathrm{T}$ ) which encodes a tyrosine kinase receptor in stem cells is known (Nagata et al., 1995; Akin, 2006). Mutated c-Kit leads to constitutive activation of affected immune cells.

In addition to antibiotics and NSAID, other commonly used drugs or substances which can lead to non-allergic hypersensitivity ADR are radio contrast media (e.g., gadolinium, iopromid), local anesthetics (e.g., bupivacaine), opioids (e.g., morphine), curare-derivatives (e.g., rocuronium), preservatives (e.g., benzoate) and coloring agents (e.g., yellow-orange S). It appears extremely variable which of these substances actually trigger a hypersensitivity $\mathrm{ADR}$ in an individual susceptible patient.

Angiotensin-converting-enzyme inhibitors inhibit bradykinine degradation as off-target effect. Polymorphisms in a kinine degrading enzyme (aminopeptidase P, XPNPEP2) are thought to contribute to angioedema (Cilia La Corte et al., 2011; Mahmoudpour et al., 2013). Bradykinine is believed to worsen inflammatory responses. There are two case report of fatalities caused by allopurinol hypersensitivity possibly aggravated by concomitant captopril or enalapril, respectively (Pennell et al., 1984; Ahmad, 1995). Based on these reports, the combination of ACEi and allopurinol is considered not recommended. However, considering that this combination is extremely common and that virtually no further fatalities were reported, the mechanistic idea that ACEi will exacerbate every hypersensitivity reaction needs to be questioned.

\section{True type I immediate ADR}

Recently, various polymorphisms in several genes have been linked to penicillin-induced immediate hypersensitivity reactions (Gueant et al., 2015). Quite surprisingly, HLA genes appear to be involved, although HLA gene products are not prominently involved in IgE-signaling to mast cells and basophils. On the other hand, both production and specificity of IgE appear to correlate with certain HLA genes (Marsh and Bias, 1977; Young et al., 1995).

Penicillines and cephalosporins are listed in the WHO Model List of Essential Medicines and prescribed world-wide. Furthermore, after NSAID, beta-lactam antibiotics are reported to be the leading cause of hypersensitivity ADR (Dona et al., 2012) and the most frequent cause for true allergies (Blanca et al., 2009). Due to the high exposure rate and the intrinsic high risk, allergic reactions are occurring frequently.

\section{Type II and Type III}

Type II and type III reactions are less commonly observed. Penicillines are known to form haptens on blood cells which are subsequently targeted by $\operatorname{IgG}$ and $\operatorname{IgM}$ antibodies causing thrombocytopenia or hemolytic anemia (type II). If betalactame antibiotics a such as pencillines are bound by IgG or IgM in the bloodstream, immune complexes form and cause intra-vascular immune reactions, e.g., vasculitis, or damage the glomeruli, e.g., glomerulonephritis (type III). To our best knowledge, there is currently no data on genetic associations to such types II and III reactions.

\section{Type IV}

Type IV ADR may lead to symptomatic or asymptomatic internal manifestations include, among others, agranulocytosis (DIA), hepatitis (DILI), nephritis (DIRI), pneumonitis and myositis. Fever and lymphadenopathies are possible. Type IV ADR can also damage the skin SCAR, e.g., DRESSs, destruction of $\sim 10 \%$ of the skin SJS and destruction of greater extend, the so called TEN. There is a certain overlap of DRESS, SJS, and TEN concerning the dermatological features.

Type IV ADR are strongly linked with a plethora of HLAgenes residing on chromosome 6. HLA-A, HLA-B, and HLA-C encode proteins that form a MHC I-receptor on various cell types for presentation of intracellular peptides to the immune system. HLA-DP, HLA-DM, HLA-DO, HLA-DQ, and HLADR are proteins for T-cell interaction, e.g., MHC II-receptors and other related proteins, consisting of alpha- and betachains encoded by separate genes. A single HLA-gene can be further specified, e.g., HLA-B* 44:02:01:02S for a HLA-B gene of allele group 44 and allele 02 . The other descriptors specify synonymous changes in the coding region, changes in the noncoding region and changes in expression. Traditional serologybased HLA typing can usually only detect the allele group of the HLA protein and not the other subtle differences below this level.

Examples of hypersensitivity-conferring HLAs and type IV ADR include abacavir + HLA-B*15:02 causing DRESS (Martin et al., 2012, 2014), carbamazepine + HLA-B*31:01 causing 
SJS/TEN (McCormack et al., 2011) and flucloxacillin + HLAB*57:01 causing DILI (Daly et al., 2009). Other related genes include Transporter Antigen Processing (TAP1/2), MHC-class I related chain $\mathrm{A} / \mathrm{B}$ (MICA/MICB) and hemochromatosis gene (High Fe, HFE). Data on T-cell receptors genes (TCRs) and killer cell immunoglobulin-like receptors (KIR) is scarce, but might prove relevant.

\section{Datasources}

Several databases exist nowadays to summarize the various findings (Table 1).

\section{Overlapping of Different Reaction Types}

Drugs can elicit hypersensitivity ADR by several non-allergic and allergic mechanisms at once, e.g., penicillines can induce immediate and delayed ADR (Blanca et al., 2009), and vancomycin can lead to both IgE-mediated and non-allergic hypersensitivity ADR (Polk et al., 1993).

To date, the different type IV reactions are not easily separated, i.e., type IVc reactions appear to be a dominant mechanism that is also occurring during types IVa, IVb, or IVd reactions (Posadas and Pichler, 2007).

Depending on the HLA-genotype, the risk agranulocytosis mediated by the antipsychotic clozapine could be significantly increased (Goldstein et al., 2014). However, a second mechanism was proposed before hypothesizing that clozapin would be metabolized to highly reactive nitrenium ions that deplete the ATP and glutathione-content of neutrophils and would ultimately lead to neutropenia (Tesfa et al., 2009).

\section{Conditions Other than Genetics Influencing Type B ADR}

The general state of the immune system may influence the occurrence or non-occurrence of ADR. E.g., vancomycinrelated red-man-syndrome is very frequently seen (up to 90\%) in non-infected, healthy patients, e.g., those receiving prophylactic treatment, but much less $(3.7-47 \%)$ in those suffering from infections (Sahai et al., 1990; Sivagnanam and Deleu, 2003). Vice versa, reactions to ampicilline (notably, not amoxicilline) are much more common in EBV-infected patients (Haverkos et al., 1991; Chew and Goenka, 2016) and reactions to sulfonamides occur predominately in HIVinfected patients (Jaffe et al., 1983).The mechanism for sulfonamide-induced hypersensitivity in HIV-patients was attributed to a decrease of cellular glutathione (Rieder et al., 1995).

TABLE 1 | Databases of genotypes and associated ADR.

\begin{tabular}{ll}
\hline Name of database & Access \\
\hline $\begin{array}{l}\text { The HLA Adverse Drug } \\
\text { Reaction Database }\end{array}$ & http://www.allelefrequencies.net/hla-adr/default.asp \\
LiverTox Database & http://livertox.nih.gov/ \\
HLADR (Du et al., 2015) & http://pgx.fudan.edu.cn/hladr/
\end{tabular}

\section{DELAYED-ONSET DRUG HYPERSENSITIVITY REACTIONS}

\section{Common Features of Drug Hypersensitivity Reactions}

It can be speculated whether the clinical manifestation of a drug hypersensitivity reactions is connected to specific genetic alterations. E.g., is there a common pool of polymorphisms leading to either DILI, DIA or SCAR? Existing data do unfortunately deny the existence of such a simple genetic constellation.

\section{Example for One Drug - One Genotype - Several Outcomes}

Allopurinol causes SJS/TEN in Han Chinese bearing HLA$B^{*} 58: 01$. At the same time, in the same population, it can cause DRESS.

\section{Example for One Drug - Several Genotypes - One Outcome}

Vice versa to the allopurinol example, nevirapine causes DRESS. It appears that the most significant HLA genotype for this reaction heavily depends on the population: HLA-B, HLA-C, and HAL-DR-loci have been associated.

\section{Example for Several Drugs - One Genotype - One Outcome}

Finally, phenytoin, phenobarbital, and carbamazepine can elicit SJS/TEN in HLA-B* 15:02 positive patients. At least this last riddle can be explained by considering the common chemical features of the three drugs (see below for details).

\section{Drug-Induced Livery Injury}

Flucloxacilline and amoxicilline/clavulanic acid are powerful first-line antibiotics which may cause DILI (Daly et al., 2009). Due to their wide-spread usage and inherent ability to cause DILI, it is vital to further understand the mechanism. Unfortunately for testing purposes, the numbers needed to screen are high and routine testing is (currently) not feasible. This in part due to the rareness of DILI which is estimated to occur in about 14 of 100,000 inhabitants per year (Bell and Chalasani, 2009). This comes unexpected when taking into account that the liver is a metabolically highly active organ, able to produce a variety of bioactivated and thus putatively immunogenic compounds from the parent drug. However, the liver is considered a tolerogenic environment, i.e., there are mostly no or locally restricted immune reactions in the liver (Crispe, 2003).

Amoxicilline/clavulanate has been linked to DILI in patients with HLA-DRB1*15:01 and recently with HLA-A*30:02, HLA-B*18:01 and the complex genotype HLA-DRB1*15:01DQB1*06:02 (Stephens et al., 2013). Interestingly, the detected populations at risk also differed in age and speed of reaction onset.

\section{Drug-Induced Agranulocytosis}

Several drugs can elicit a life-threatening destruction of blood cells. E.g., the antipsychotic clozapine is commonly 
( $0.8 \%$ of drug users) causing neutropenia (less than 1500 neutrophil granulocytes/ $\mu \mathrm{l}$ ) or agranulocytosis (less than 500 granulocytes/ $\mu \mathrm{l})$. Other triggering drugs for DIA comprise thyreostatics like methimazole and the analgesic metamizole (USAN: dipyrone). Pharmacogenetic associations are known for methimazole and HLA-DRB1*08:03:2 (Tamai et al., 1996), for metamizole and various HLA genotypes (Vlahov et al., 1996) and for clozapine and a complex HLA genotype in Jewish subjects (Lieberman et al., 1990) for more than two decades.

Since clozapine appears to be the most effective antipsychotic drug available, there is a need to increase our understanding of its safe or putatively unsafe usage. The initial findings for clozapine were subsequently refined and applied to the general population (Dettling et al., 2001). Various polymorphisms leading to DIA after clozapine exposure have been identified, e.g., a complex genotype consisting of HLA-DRB5-DRB4, HLA-CB-DRB5 (Dettling et al., 2007), HLA-DQB1 (Athanasiou et al., 2011), HLA-DQB1 (126Q) and HLA-B (158T) (Goldstein et al., 2014). The latter two studies deserve additional attention since the association was identified to be due to single amino acid changes at a defined position in the HLA gene product rather than to alleles described before. This is similar to the incidental finding that a single amino acid change in HLA-A, HLA-B, and HLA-C at position 152 might explain altered susceptibility of T-cells to drugs and lead to DILI (Stephens et al., 2013). Amino acids exchanges at this position alter the antigen binding pocket $\mathrm{E}$ of the MHC I receptor and possibly the interaction with T-cells. These findings suggest that a single amino acid change and not a serology-derived typing of HLA may provide a better prediction of the observed hypersensitivity reaction because of the mechanistical explanation inferred by the change in the binding pocket.

\section{Severe Cutaneous ADR}

Next to the liver, the skin, including the mucosa, is involved in bioactivation of drugs. Additionally, since the skin is the barrier that protects our body from the environment, it is rich of immune cells. Due to this combination of a huge amount of putatively immunogenic compounds, an abundancy of immune cells and the constant pre-sensitization of the dermal immune cells due to their contact with pathogens, the skin is a prime location for the manifestation of immune reactions. It has been proposed that the increased reactivity of EBV- or HIV-infected patients to aminopenicillines might be due to a lower activation threshold of T-cells (Posadas and Pichler, 2007). Differential pathways of activation have been show for flucloxacillin (Yaseen et al., 2015).

Severe cutaneous ADR encompass DRESS and SJS/TEN. Commonly used substances which can cause SCAR are abacavir, lamotrigine, and carbamazepine (Pirmohamed et al., 2015). The latter has an aromatic moiety and is grouped together with phenobarbital and phenytoin to the aromatic anticonvulsants. These aromatic anticonvulsants were associated with various HLA-A and HLAB variants. Interestingly, a hypersensitivity reaction to the non-aromatic drug lamotrigine was recently also associated to HLA-B* 15:02 and SJS in a Han Chinese population (Man et al., 2007; Zeng et al., 2015).
The finding that abacavir is very likely to induce DRESS in HLA-B*57:01 positive patients led to a guideline of the CPIC which recommends testing because of the severity of the reaction and the high risk in absence of genetic prescreening (Martin et al., 2012). It is estimated that $6 \%$ in the general population are carriers of HLA-B*57:01 and that around 50\% of carrier will develop DRESS. The recommendation is thus classified as "strong." However, it was argued that $50 \%$ of positively tested individuals will be denied an effective treatment option (Martin et al., 2012). Therefore, CPIC reviews guidelines on a regular basis. Recently, the unchanged recommendation was confirmed (Martin et al., 2014).

Table 2 summarizes all affected drugs and clinical manifestations of late-onset hypersensitivity reactions.

\section{ISSUES IN DATA ACQUISITION AND INTERPRETATION}

\section{The Input}

As nicely illustrated by the abacavir example, any improvement of signal detection and risk calculations requires correct assessment of the event (Phillips et al., 2011). Physicians in clinics tend

TABLE 2 | Manifestations of late-onset hypersensitivity reactions and commonly affected drugs.

\begin{tabular}{|c|c|c|}
\hline Affected organ & Clinical manifestation & Drugs involved \\
\hline \multirow[t]{7}{*}{ Liver } & Anorexia & Flucloxacilline \\
\hline & Fatigue & Amoxicilline \\
\hline & Nausea & \\
\hline & Abdominal pain & \\
\hline & Jaundice/itching & \\
\hline & Blood clotting disorders & \\
\hline & $\begin{array}{l}\text { Blood tests: elevated liver } \\
\text { function tests (ALAT, ASAT) }\end{array}$ & \\
\hline \multirow[t]{6}{*}{ Granulocytes } & Agranulocytosis: & $\begin{array}{l}\text { Metamizole } \\
\text { (Dipyrone) }\end{array}$ \\
\hline & Sudden fever & Clozapine \\
\hline & Sore throat & $\begin{array}{l}\text { Carbimazol/ } \\
\text { Thiamazol/Methimazole }\end{array}$ \\
\hline & $\begin{array}{l}\text { Infections (urinary tract, } \\
\text { pneumonia) }\end{array}$ & \\
\hline & Sepsis & \\
\hline & $\begin{array}{l}\text { Blood tests: low leukocyte } \\
\text { counts }\end{array}$ & \\
\hline \multirow[t]{10}{*}{ Skin } & DRESS: & Allopurinol \\
\hline & Fever & Abacavir \\
\hline & Edema (face) & \\
\hline & Exanthema & \\
\hline & Lymphadenopathies & \\
\hline & $\begin{array}{l}\text { Blood tests: eosinophilia, } \\
\text { thrombocytopenia, anemia }\end{array}$ & \\
\hline & SJS/TEN: & Lamotrigine \\
\hline & severe necrosis of the skin & Carbamazepine \\
\hline & & Phenobarbital \\
\hline & & Phenytoin \\
\hline
\end{tabular}


sometimes to misdiagnose the reaction, focus on only one aspect, fail to conduct further investigations that would strengthen or invalidate the finding, or fail to document the event appropriately (Thien, 2006). The solution that worked for the abacavir-findings was to conduct two tests, both a clinical assessment using a structured query form and a skin patch test to confirm involvement of the immune system (Phillips et al., 2011).

Starting with the thalidomide tragedy, the powerful pharmacovigilance system was installed in most countries. The strength of this system is the huge data pool on adverse events like ADR encompassing millions of cases world-wide. A major drawback is the paucity of information routinely entered into this systems (Böhm et al., 2016). Genetic information is usually missing and the patients mentioned in the individual safety reports cannot be recontacted for further investigations. It is thus only possible to generate hypotheses which need further evaluation.

\section{The Throughput}

To increase the collection of cases and their quality, interested parties have formed their own collaborative research teams, e.g., RegiSCAR for severe cutaneous reactions (Phillips et al., 2011), the Berlin Case-Control Surveillance Study group (e.g., Huber et al., 2015) and the International CIA Consortium for DIA or DILIGEN, iDILIC, DILIN, and others focusing on DILI (Nicoletti et al., 2016). These networks allow standardized collection of patient and event data as well as genetic material, and possibly re-identification of patients for further data or material sampling.

Of note, such a network requires tremendous resources if the drug-event-combination is rare. E.g., finding the association of flupirtine and HLA-DRB1*16:01-DQB1*05:02 causing DILI took more than 10 years of careful preparation and data collection (Nicoletti et al., 2016). The Berlin Case-Control Surveillance Study group collected data for 10 years (Huber et al., 2015). The increasing availability of electronic health records, the ongoing deployment of biobanks and the advances regarding the accompanying ethical, legal, technical, and social challenges (Strech et al., 2016) might deliver a global new data source for research on drug hypersensitivity reactions.

\section{The Output}

All data essentially boils down to a $2 \times 2$ contingency table of one biomarker and the occurrence of the ADR. Several statistical measurements can be derived from this: $p$-values (e.g., derived from Chi squared with Yates' correction), odds ratios, sensitivity/specificity, PPV, NPV as well as NNS.

It is sometimes desirable to combine several polymorphisms to a complex genotype or, analogously, several drugs to one drug class or several reactions to a syndrome. Grouping of individual findings will enhance the usefulness of the data for constructing novel detection techniques and to reach statistical and clinical significance (Böhm et al., 2016). E.g., genotyping of individual polymorphisms in cases of clozapineinduced agranulocytosis revealed no findings, whereas grouping polymorphisms to complex genotypes revealed three associations (Dettling et al., 2007). Another example is the $75 \%$ crossreactivity of carbamazepine, phenytoine and phenobarbital and possibly lamotrigine on SJS/TEN. Arene oxide is a common moiety of metabolites of the first three anticonvulsant drugs and is considered to be the immunologic active substance. Grouping these drugs might help to strengthen signals for certain polymorphisms.

Traditional statistical approaches are not suited for analyses of small numbers. The fewer cases are reported, the wider the 95\%confidence interval becomes. The work of iDILIC shows that it is possible to find a convincing signal with just six cases (Nicoletti et al., 2016). However, in the future Bayesian approaches are expected to replace traditional frequentists' methods for such small numbers of cases (Yum et al., 2014). Bayesian statistics is increasingly used in early clinical trials in order to efficiently screen for signals where numbers are low.

Each of the statistical measurements given above should be used for different purposes:

(i) Statistical significance: the $p$-value marks the feasibility for further calculations of this drug-biomarker-reactionassociation.

(ii) Technical significance: sensitivity/specificity are useful for test validation only. They have no direct value for the patient or the health system. Of course, the higher these values are, the better the following resulting measurements.

(iii) Clinical significance: PPD and NPD reflect the personal risk for an individual patient. E.g., if a drug hypersensitivity reaction is extremely rare, a positive test for a biomarker does not automatically suggest a high predictive value. PPD and NPD will guide which further clinical investigations should be conducted or which treatment options are feasible.

(iv) Economic significance: the NNS will be used by the stakeholders of the heath system. The NNS allows to estimate the how many patients need to be screened to prevent one case of ADR. Depending on the costs of the screening procedure and the severity of the ADR, different cut-off values for NNS will be used. Time will show whether and to what extend pharmacogenetic tests will decrease the overall treatment costs for prediction of drug hypersensitivity reactions. Current evaluations estimate a plain decrease of costs for the health system (Alagoz et al., 2016).

Table 3 shows several examples where statistical, technical, clinical and economic significance differ.

The example of the pooled data (dataset \#3) as extracted from the HLADR database shows that combining data does not substantially improve PPV, NPV, or NNS if the individual datasets are of sufficient quality (Mallal et al., 2002; Martin et al., 2004).

A common problem is the acquisition of data due to the low numbers of cases and matching controls: often, not all cells of the $2 \times 2$ contingency table contain a count. Zero counts are problematic for the calculation of measurements of disproportionality. There are several ways to cope with this situation: A mathematical tool is the usage of Haldane's modification for Odds Ratios. By adding 0.5 to every cell, zero counts are eliminated. Another option is carefully matching other 
TABLE 3 | Showcases of associations of drug - biomarker - event and derived statistical measurements.

\begin{tabular}{|c|c|c|c|c|c|c|c|c|c|c|c|}
\hline$\#$ & $\begin{array}{l}\text { Drug-biomarker- } \\
\text { event }\end{array}$ & BE & $\mathrm{Be}$ & bE & be & $p$-value & $\begin{array}{l}\text { Sensitivity/ } \\
\text { specificity }\end{array}$ & $\begin{array}{c}\text { Prevalence or } \\
\text { incidence of } \\
\text { event }\end{array}$ & PPV/NPV & NNS & Datasource \\
\hline 1 & $\begin{array}{l}\text { Abacavir - } \\
\text { HLA-B*57:01 - } \\
\text { DRESS/AHSS }\end{array}$ & 14 & 4 & 4 & 163 & $<0.01$ & $77.8 / 97.6 \%$ & $8 \% *$ & $77.8 / 97.6 \%$ & $16.58^{*}$ & $\begin{array}{l}\text { FD1 HLADR (Mallal } \\
\text { et al., 2002) }\end{array}$ \\
\hline 2 & $\begin{array}{l}\text { Abacavir - } \\
\text { HLA-B*57:01 - } \\
\text { DRESS/AHSS }\end{array}$ & 17 & 4 & 1 & 226 & $<0.01$ & $94.4 / 98.3 \%$ & $8 \% *$ & $78.9 / 99.4 \%$ & $15.53^{*}$ & $\begin{array}{l}\text { FD4 HLADR (Martin } \\
\text { et al., 2004) }\end{array}$ \\
\hline 3 & $\begin{array}{l}\text { Abacavir - } \\
\text { HLA-B*57:01 - } \\
\text { DRESS/AHSS }\end{array}$ & 31 & 8 & 5 & 389 & $<0.01$ & $86.1 / 97.9 \%$ & $8 \% *$ & $79.5 / 98.7 \%$ & $16.25^{*}$ & $\begin{array}{l}\text { Pooled FD1+FD4 } \\
\text { (Mallal et al., 2002; } \\
\text { Martin et al., 2004) }\end{array}$ \\
\hline 4 & $\begin{array}{l}\text { Abacavir - complex } \\
\text { genotype HLA-B*57:01 } \\
+ \text { DR7 + DQ3 - } \\
\text { DRESS/AHSS }\end{array}$ & 13 & 0 & 5 & 167 & $<0.01$ & $72 / 100 \%$ & $8 \% *$ & $100 / 96.9 \%$ & $\sim 12.5^{*}$ & Mallal et al., 2002 \\
\hline 5 & $\begin{array}{l}\text { Flupirtin - complex } \\
\text { genotype } \\
\text { HLA-DRB1*16:01 + } \\
\text { DQB1*05:02 - DILI }\end{array}$ & 11 & 0 & 614 & 10588 & $<0.01$ & $1.8 / 100 \%$ & 13.9:100,000* & $100 / 94.5 \%$ & 〜8000* & Nicoletti et al., 2016 \\
\hline 6 & $\begin{array}{l}\text { Flucloxacilline - } \\
\text { HLA-*57:01 - DILI }\end{array}$ & 43 & 8 & 4 & 60 & $<0.01$ & $84.3 / 93.75 \%$ & $8.5: 100,000$ & $0.12 / 99.99 \%$ & $\sim 13,000$ & Daly et al., 2009 \\
\hline
\end{tabular}

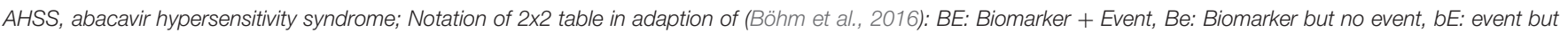

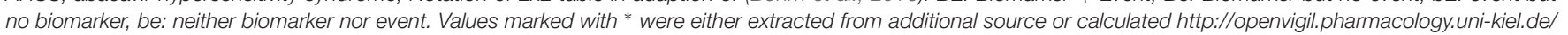
contingency-table-calculator.php. FD\# HLADR denotes the number of dataset obtained from http://pgx.fudan.edu.cn/hladr/.

(known) cohorts to the existing data (Nicoletti et al., 2016). The theoretical gold standard is to keep gathering reports until all cells can be filled in with sufficiently large counts which is often not feasible.

The full dataset (\#4) using complex genotypes illustrates that the combination of genotypes enhances the performance of the test, in this case the PPV (Mallal et al., 2002).

The dataset \#5 illustrates that even test with an extremely low sensitivity can lead to acceptable high PPV and NPV and thus NNS (Nicoletti et al., 2016).

The findings in dataset \#6 shows a scenario in which testing appears very reasonable if calculating PPV and NPV from the original data $(\mathrm{PPV}=91.49 \%, \mathrm{NPV}=88.23 \%$, NNS $=1.3$ ). However, when applying the real population-wide prevalence instead of relying solely on the counts reported in this publication, a much lower PPD of $0.12 \%$ results and thus a very high NNS of approximately 13,000 (Daly et al., 2009). Still, testing is desirable from the patient's point of view (NPV 100\%). However, it is economically not feasible.

\section{WHEN AND HOW TO TEST FOR A RISK OF HYPERSENSITIVITY}

From a clinical point of view, testing for pharmacogenetics markers for the prediction of drug hypersensitivity reactions is only useful if

(i) a test with sufficient PPV/NPV exists,

(ii) an alternative treatment or diagnostic option exist that can be employed on a positive test result and

(iii) the test is unlikely to inflict damage on the patient.
From an economically point of view, it might be added:

(iv) testing of the population at risk should be cheaper than the costs to treat ADR in this population, implying a low NNS.

Of note, the NNS requires knowledge of the prevalence to be calculated. Due to the rareness of the events being analyzed, in most cases just estimates of the incidence-rates in a subpopulation (primarily users of the drug) are known. Consequently, NNS figures will vary depending on these epidemiologic data. Table 4 lists the drugs for which currently a genetic testing prior to exposition is mandatory.

Sometimes, more than one test for a risk-predicting factor is available. Under most circumstances, phenotyping requires more time and could potentially damage the patient. E.g., the risk of a drug hypersensitivity reactions to abacavir can be assessed in a variety of ways: a genetic test for HLA-B*57:01, an ex vivo test like lymphocyte transformation test (LTT) and in vivo tests like a skin patch test or an oral challenge (Rive et al., 2013). The genetic test and the LTT bear no risk for the patient. The genetic test needs no cultivation of cells and is thus much cheaper than the LTT. The skin patch might induce a reaction and the oral challenge option cannot be used due to severe drug hypersensitivity reactions.

TABLE 4 | Drugs for which currently pharmacogenetics testing is mandatory.

\begin{tabular}{ll}
\hline Drug & Biomarker \\
\hline Abacavir & HLA- B*57:01 \\
Carbamazepine & Only for Thai and Han Chinese: HLA-B*15:02
\end{tabular}

Not included are any test for the existence or subsceptibility of the pharmacodynamic target (e.g., kinase inhibiting oncologic drugs and the required prior genetic testing for a mutation in the kinase). 
Human leukocyte antigen typing can also be done using serology, i.e., antibodies directed at certain surface proteins. However, the accuracy of this method is lower $(7.1 \%$ misassignments) than genetic HLA typing (Bozon et al., 1996). Subtle changes of the HLA-encoded proteins are usually not detectable with serology-based methods. It is doubtful whether binding pockets to drugs or other interacting proteins (e.g., $\mathrm{T}$ cell receptors) are being recognized by the currently employed antibodies in serology-based HLA typing.

Summarizing, genetic tests have been proven to be usually the safest, fastest, and cheapest screening tool.

\section{CONCLUSION}

Adverse drug reaction are a major burden for the health care system. A large percentage could be prevented. Pharmacogenetic testing can contribute to avoidance of ADR, both pharmacological ADR (type A) and drug hypersensitivity reactions (type $\mathrm{B}$ ADR). Certain alleles and complex genotypes

\section{REFERENCES}

Agundez, J. A., Ayuso, P., Cornejo-Garcia, J. A., Blanca, M., Torres, M. J., Dona, I., et al. (2012). The diamine oxidase gene is associated with hypersensitivity response to non-steroidal anti-inflammatory drugs. PLoS ONE 7:e47571. doi: 10.1371/journal.pone.0047571

Ahmad, S. (1995). Allopurinol and enalapril. Drug induced anaphylactic coronary spasm and acute myocardial infarction. Chest 108:586. doi: $10.1378 /$ chest.108.2.586

Akin, C. (2006). Molecular diagnosis of mast cell disorders: a paper from the 2005 William Beaumont Hospital Symposium on Molecular Pathology. J. Mol. Diagn. 8, 412-419. doi: 10.2353/jmoldx.2006.060022

Alagoz, O., Durham, D., and Kasirajan, K. (2016). Cost-effectiveness of one-time genetic testing to minimize lifetime adverse drug reactions. Pharmacogenomics J. 16, 129-136. doi: 10.1038/tpj.2015.39

Athanasiou, M. C., Dettling, M., Cascorbi, I., Mosyagin, I., Salisbury, B. A., Pierz, K. A., et al. (2011). Candidate gene analysis identifies a polymorphism in HLADQB1 associated with clozapine-induced agranulocytosis. J. Clin. Psychiatry 72, 458-463. doi: 10.4088/JCP.09m05527yel

Ayuso, P., Blanca, M., Cornejo-Garcia, J. A., Torres, M. J., Dona, I., Salas, M., et al. (2013). Variability in histamine receptor genes HRH1, HRH2 and HRH4 in patients with hypersensitivity to NSAIDs. Pharmacogenomics 14, 1871-1878. doi: $10.2217 /$ pgs.13.155

Bell, L. N., and Chalasani, N. (2009). Epidemiology of idiosyncratic drug-induced liver injury. Semin. Liver Dis. 29, 337-347. doi: 10.1055/s-0029-1240002

Blanca, M., Romano, A., Torres, M. J., Fernandez, J., Mayorga, C., Rodriguez, J., et al. (2009). Update on the evaluation of hypersensitivity reactions to betalactams. Allergy 64, 183-193. doi: 10.1111/j.1398-9995.2008.01924.x

Böhm, R., Von Hehn, L., Herdegen, T., Klein, H. J., Bruhn, O., Petri, H., et al. (2016). Open vigil FDA - inspection of U.S. American adverse drug events pharmacovigilance data and novel clinical applications. PLoS ONE 11:e0157753. doi: 10.1371 /journal.pone.0157753

Borda, I. T., Slone, D., and Jick, H. (1968). Assessment of adverse reactions within a drug surveillance program. JAMA 205, 645-647. doi: 10.1001/jama.205.9.645

Bouvy, J. C., De Bruin, M. L., and Koopmanschap, M. A. (2015). Epidemiology of adverse drug reactions in Europe: a review of recent observational studies. Drug Safety 38, 437-453. doi: 10.1007/s40264-015-0281-0

Bozon, M. V., Delgado, J. C., Turbay, D., Salazar, M., Granja, C. B., Alosco, S. M., et al. (1996). Comparison of HLA-A antigen typing by serology with two polymerase chain reaction based DNA typing methods: implications for proficiency testing. Tissue Antigens 47, 512-518. doi: 10.1111/j.13990039.1996.tb02593.x of HLA genes contribute to drug hypersensitivity reactions. Common drug hypersensitivity reactions include cytotoxicity in skin, liver, and blood cells. The decision for HLA genotyping before drug therapy is dependent on severity of the expected $\mathrm{ADR}$ and the existence of other treatment options, as well as a reasonable high positive and NPVs of the test in question in the population to be analyzed.

\section{AUTHOR CONTRIBUTIONS}

IC and $\mathrm{RB}$ did the literature research. $\mathrm{RB}$ and IC wrote the manuscript.

\section{FUNDING}

We acknowledge financial support by Land Schleswig-Holstein within the funding program Open Access Publikationsfonds.

Brockmoller, J., Kirchheiner, J., Schmider, J., Walter, S., Sachse, C., MullerOerlinghausen, B., et al. (2002). The impact of the CYP2D6 polymorphism on haloperidol pharmacokinetics and on the outcome of haloperidol treatment. Clin. Pharmacol. Ther. 72, 438-452. doi: 10.1067/mcp.2002.127494

Canto, M. G., Andreu, I., Fernandez, J., and Blanca, M. (2009). Selective immediate hypersensitivity reactions to NSAIDs. Curr. Opin. Allergy Clin. Immunol. 9, 293-297. doi: 10.1097/ACI.0b013e32832db943

Chew, C., and Goenka, A. (2016). QUESTION 2: does amoxicillin exposure increase the risk of rash in children with acute Epstein-Barr virus infection? Arch. Dis. Childhood 101, 500-502. doi: 10.1136/archdischild-2015-310364

Cilia La Corte, A. L., Carter, A. M., Rice, G. I., Duan, Q. L., Rouleau, G. A., Adam, A., et al. (2011). A functional XPNPEP2 promoter haplotype leads to reduced plasma aminopeptidase $\mathrm{P}$ and increased risk of ACE inhibitor-induced angioedema. Hum. Mutat. 32, 1326-1331. doi: 10.1002/humu.21579

Crispe, I. N. (2003). Hepatic T cells and liver tolerance. Nature Reviews. Immunol. 3, 51-62. doi: 10.1038/nri981

Daly, A. K., Donaldson, P. T., Bhatnagar, P., Shen, Y., Pe'er, I., Floratos, A., et al. (2009). HLA-B*5701 genotype is a major determinant of drug-induced liver injury due to flucloxacillin. Nat. Genet. 41, 816-819. doi: 10.1038/ng.379

Demoly, P., Lebel, B., Messaad, D., Sahla, H., Rongier, M., Daures, J., et al. (1999). Predictive capacity of histamine release for the diagnosis of drug allergy. Allergy 54, 500-506. doi: 10.1034/j.1398-9995.1999.00020.x

Dettling, M., Cascorbi, I., Opgen-Rhein, C., and Schaub, R. (2007). Clozapineinduced agranulocytosis in schizophrenic Caucasians: confirming clues for associations with human leukocyte class I and II antigens. Pharmacogenomics J. 7, 325-332. doi: 10.1038/sj.tpj.6500423

Dettling, M., Cascorbi, I., Roots, I., and Mueller-Oerlinghausen, B. (2001). Genetic determinants of clozapine-induced agranulocytosis: recent results of HLA subtyping in a non-jewish caucasian sample. Arch. Gen. Psychiatry 58, 93-94. doi: 10.1001/archpsyc.58.1.93

Dona, I., Blanca-Lopez, N., Torres, M. J., Garcia-Campos, J., Garcia-Nunez, I., Gomez, F., et al. (2012). Drug hypersensitivity reactions: response patterns, drug involved, and temporal variations in a large series of patients. J. Investig. Allergol. Clin. Immunol. 22, 363-371.

Du, T., Yang, L., Luo, H., Zhou, P., Mei, H., Xuan, J., et al. (2015). HLADR: a database system for enhancing the discovery of biomarkers for predicting human leukocyte antigen-mediated idiosyncratic adverse drug reactions. Biomark. Med. 9, 1079-1093. doi: 10.2217/bmm.15.98

Estivill, X., Govea, N., Barcelo, E., Badenas, C., Romero, E., Moral, L., et al. (1998). Familial progressive sensorineural deafness is mainly due to the mtDNA A1555G mutation and is enhanced by treatment of aminoglycosides. Am. J. Hum. Genet. 62, 27-35. doi: 10.1086/301676 
Goldstein, J. I., Jarskog, L. F., Hilliard, C., Alfirevic, A., Duncan, L., Fourches, D., et al. (2014). Clozapine-induced agranulocytosis is associated with rare HLADQB1 and HLA-B alleles. Nat. Commun. 5:4757. doi: 10.1038/ncomms5757

Gomez, F., Perkins, J. R., Garcia-Martin, E., Canto, G., and Cornejo-Garcia, J. A. (2015). Genetic basis of hypersensitivity reactions to nonsteroidal antiinflammatory drugs. Curr. Opin. Allergy Clin. Immunol. 15, 285-293. doi: 10.1097/ACI.0000000000000178

Gueant, J. L., Romano, A., Cornejo-Garcia, J. A., Oussalah, A., Chery, C., BlancaLopez, N., et al. (2015). HLA-DRA variants predict penicillin allergy in genomewide fine-mapping genotyping. J. Allergy Clin. Immunol. 135, 253-259. doi: 10.1016/j.jaci.2014.07.047

Haverkos, H. W., Amsel, Z., and Drotman, D. P. (1991). Adverse virus-drug interactions. Rev. Infect. Dis. 13, 697-704. doi: 10.1093/clinids/13.4.697

Huber, M., Andersohn, F., Sarganas, G., Bronder, E., Klimpel, A., Thomae, M., et al. (2015). Metamizole-induced agranulocytosis revisited: results from the prospective Berlin case-control surveillance study. Eur. J. Clin. Pharmacol. 71, 219-227. doi: 10.1007/s00228-014-1777-8

Innocenti, F., Kroetz, D. L., Schuetz, E., Dolan, M. E., Ramirez, J., Relling, M., et al. (2009). Comprehensive pharmacogenetic analysis of irinotecan neutropenia and pharmacokinetics. J. Clin. Oncol. 27, 2604-2614. doi: 10.1200/JCO.2008.20.6300

Jaffe, H. S., Abrams, D. I., Ammann, A. J., Lewis, B. J., and Golden, J. A. (1983). Complications of co-trimoxazole in treatment of AIDS-associated Pneumocystis carinii pneumonia in homosexual men. Lancet 2, 1109-1111. doi: 10.1016/S0140-6736(83)90627-X

Kim, S. H., Oh, J. M., Kim, Y. S., Palmer, L. J., Suh, C. H., Nahm, D. H., et al. (2006). Cysteinyl leukotriene receptor 1 promoter polymorphism is associated with aspirin-intolerant asthma in males. Clin. Exp. Allergy 36, 433-439. doi: 10.1111/j.1365-2222.2006.02457.x

Lieberman, J. A., Yunis, J., Egea, E., Canoso, R. T., Kane, J. M., and Yunis, E. J. (1990). HLA-B38, DR4, DQw3 and clozapine-induced agranulocytosis in Jewish patients with schizophrenia. Arch. Gen. Psychiatry 47, 945-948. doi: 10.1001/archpsyc.1990.01810220061007

Mahmoudpour, S. H., Leusink, M., Van Der Putten, L., Terreehorst, I., Asselbergs, F. W., De Boer, A., et al. (2013). Pharmacogenetics of ACE inhibitorinduced angioedema and cough: a systematic review and meta-analysis. Pharmacogenomics 14, 249-260. doi: 10.2217/pgs.12.206

Mallal, S., Nolan, D., Witt, C., Masel, G., Martin, A. M., Moore, C., et al. (2002). Association between presence of HLA-B*5701, HLA-DR7, and HLA-DQ3 and hypersensitivity to HIV-1 reverse-transcriptase inhibitor abacavir. Lancet 359, 727-732. doi: 10.1016/S0140-6736(02)07873-X

Man, C. B., Kwan, P., Baum, L., Yu, E., Lau, K. M., Cheng, A. S., et al. (2007). Association between HLA-B*1502 allele and antiepileptic druginduced cutaneous reactions in Han Chinese. Epilepsia 48, 1015-1018. doi: 10.1111/j.1528-1167.2007.01022.x

Marsh, D. G., and Bias, W. B. (1977). Basal serum IgE levels and HLA antigen frequencies in allergic subjects. Immunogenetics 5, 235-251. doi: 10.1007/BF01570478

Martin, A. M., Nolan, D., Gaudieri, S., Almeida, C. A., Nolan, R., James, I., et al. (2004). Predisposition to abacavir hypersensitivity conferred by HLAB*5701 and a haplotypic Hsp70-Hom variant. Proc. Natl. Acad. Sci. U.S.A. 101, 4180-4185. doi: 10.1073/pnas.0307067101

Martin, M. A., Hoffman, J. M., Freimuth, R. R., Klein, T. E., Dong, B. J., Pirmohamed, M., et al. (2014). Clinical pharmacogenetics implementation consortium guidelines for HLA-B genotype and abacavir dosing: 2014 update. Clin. Pharmacol. Ther. 95, 499-500. doi: 10.1038/clpt.2014.38

Martin, M. A., Klein, T. E., Dong, B. J., Pirmohamed, M., Haas, D. W., and Kroetz, D. L. (2012). Clinical pharmacogenetics implementation consortium guidelines for HLA-B genotype and abacavir dosing. Clin. Pharmacol. Ther. 91, 734-738. doi: 10.1038/clpt.2011.355

McCormack, M., Alfirevic, A., Bourgeois, S., Farrell, J. J., Kasperaviciute, D., Carrington, M., et al. (2011). HLA-A*3101 and carbamazepine-induced hypersensitivity reactions in Europeans. N. Engl. J. Med. 364, 1134-1143. doi: 10.1056/NEJMoa1013297

Meier, F., Maas, R., Sonst, A., Patapovas, A., Muller, F., Plank-Kiegele, B., et al. (2015). Adverse drug events in patients admitted to an emergency department: an analysis of direct costs. Pharmacoepidemiol. Drug Saf. 24, 176-186. doi: $10.1002 /$ pds. 3663
Mjorndal, T., Boman, M. D., Hagg, S., Backstrom, M., Wiholm, B. E., Wahlin, A., et al. (2002). Adverse drug reactions as a cause for admissions to a department of internal medicine. Pharmacoepidemiol. Drug Saf. 11, 65-72. doi: 10.1002/pds.667

Molnar-Gabor, E., Endreffy, E., and Rozsasi, A. (2000). HLA-DRB1, -DQA1, and -DQB1 genotypes in patients with nasal polyposis. Laryngoscope 110, 422-425. doi: 10.1097/00005537-200003000-00017

Myers, A. L., Gaedigk, A., Dai, H., James, L. P., Jones, B. L., and Neville, K. A. (2012). Defining risk factors for red man syndrome in children and adults. Pediatr. Infect. Dis. J. 31, 464-468. doi: 10.1097/INF.0b013e31824e10d7

Nagata, H., Worobec, A. S., Oh, C. K., Chowdhury, B. A., Tannenbaum, S., Suzuki, Y., et al. (1995). Identification of a point mutation in the catalytic domain of the protooncogene c-kit in peripheral blood mononuclear cells of patients who have mastocytosis with an associated hematologic disorder. Proc. Natl. Acad. Sci. U.S.A. 92, 10560-10564. doi: 10.1073/pnas.92.23.10560

Nicoletti, P., Werk, A. N., Sawle, A., Shen, Y., Urban, T. J., Coulthard, S. A., et al. (2016). HLA-DRB1*16: 01-DQB1*05: 02 is a novel genetic risk factor for flupirtine-induced liver injury. Pharmacogenetics Genom. 26, 218-224. doi: 10.1097/FPC.0000000000000209

Park, S. M., Park, J. S., Park, H. S., and Park, C. S. (2013). Unraveling the genetic basis of aspirin hypersensitivity in asthma beyond arachidonate pathways. Allergy Asthma Immunol. Res. 5, 258-276. doi: 10.4168/aair.2013.5.5.258

Pennell, D. J., Nunan, T. O., O'doherty, M. J., and Croft, D. N. (1984). Fatal stevensjohnson syndrome in a patient on captopril and allopurinol. Lancet 1:463. doi: 10.1016/S0140-6736(84)91807-5

Phillips, E. J., Chung, W. H., Mockenhaupt, M., Roujeau, J. C., and Mallal, S. A. (2011). Drug hypersensitivity: pharmacogenetics and clinical syndromes. J. Allergy Clin. Immunol. 127, S60-S66. doi: 10.1016/j.jaci.2010.11.046

Pierce, A., and Nester, T. (2011). Pathology consultation on druginduced hemolytic anemia. Am. J. Clin. Pathol. 136, 7-12. doi: 10.1309/AJCPBVLJZH6W6RQM

Pirmohamed, M., Ostrov, D. A., and Park, B. K. (2015). New genetic findings lead the way to a better understanding of fundamental mechanisms of drug hypersensitivity. J. Allergy Clin. Immunol. 136, 236-244. doi: 10.1016/j.jaci.2015.06.022

Polk, R. E., Israel, D., Wang, J., Venitz, J., Miller, J., and Stotka, J. (1993). Vancomycin skin tests and prediction of "red man syndrome" in healthy volunteers. Antimicrob. Agents Chemother. 37, 2139-2143. doi: 10.1128/AAC.37.10.2139

Posadas, S. J., and Pichler, W. J. (2007). Delayed drug hypersensitivity reactions - new concepts. Clin. Exp. Allergy 37, 989-999. doi: 10.1111/j.13652222.2007.02742.x

Rieder, M. J., Krause, R., Bird, I. A., and Dekaban, G. A. (1995). Toxicity of sulfonamide-reactive metabolites in HIV-infected, HTLV-infected, and noninfected cells. J. Acquired Immune Defic. Syndr. Hum. Retrovirol. 8, 134140. doi: 10.1097/00042560-199502000-00004

Rive, C. M., Bourke, J., and Phillips, E. J. (2013). Testing for drug hypersensitivity syndromes. Clin. Biochemist. Rev. 34, 15-38.

Sahai, J., Healy, D. P., Shelton, M. J., Miller, J. S., Ruberg, S. J., and Polk, R. (1990). Comparison of vancomycin- and teicoplanin-induced histamine release and "red man syndrome". Antimicrob. Agents Chemother. 34, 765-769. doi: 10.1128/AAC.34.5.765

Sivagnanam, S., and Deleu, D. (2003). Red man syndrome. Crit. Care 7, 119-120. doi: $10.1186 / \mathrm{cc} 1871$

Stephens, C., Lopez-Nevot, M. A., Ruiz-Cabello, F., Ulzurrun, E., Soriano, G., Romero-Gomez, M., et al. (2013). HLA alleles influence the clinical signature of amoxicillin-clavulanate hepatotoxicity. PLoS ONE 8:e68111. doi: 10.1371/journal.pone.0068111

Strech, D., Bein, S., Brumhard, M., Eisenmenger, W., Glinicke, C., Herbst, T., et al. (2016). A template for broad consent in biobank research. Results and explanation of an evidence and consensus-based development process. Eur. J. Med. Genet. 59, 295-309. doi: 10.1016/j.ejmg.2016.04.002

Suchak, R., Benson, K., and Swale, V. (2007). Statin-induced Ro/SSa-positive subacute cutaneous lupus erythematosus. Clin. Exp. Dermatol. 32, 589-591. doi: 10.1111/j.1365-2230.2007.02488.x

Tamai, H., Sudo, T., Kimura, A., Mukuta, T., Matsubayashi, S., Kuma, K., et al. (1996). Association between the DRB1*08032 histocompatibility antigen and methimazole-induced agranulocytosis in Japanese patients with Graves disease. 
Ann. Intern. Med. 124, 490-494. doi: 10.7326/0003-4819-124-5-19960301000005

Tesfa, D., Keisu, M., and Palmblad, J. (2009). Idiosyncratic drug-induced agranulocytosis: possible mechanisms and management. Am. J. Hematol. 84, 428-434. doi: 10.1002/ajh.21433

Thien, F. C. (2006). 3. Drug hypersensitivity. Med. J. Aust. 185, 333-338.

Usami, S., Abe, S., Shinkawa, H., and Kimberling, W. J. (1998). Sensorineural hearing loss caused by mitochondrial DNA mutations: special reference to the A1555G mutation. J. Commun. Disord. 31, 423-434; quiz 434-425.. doi: 10.1016/S0021-9924(98)00014-8

Vlahov, V., Bacracheva, N., Tontcheva, D., Naumova, E., Mavrudieva, M., Ilieva, P., et al. (1996). Genetic factors and risk of agranulocytosis from metamizol. Pharmacogenetics 6, 67-72. doi: 10.1097/00008571-199602000-00005

Yaseen, F. S., Saide, K., Kim, S. H., Monshi, M., Tailor, A., Wood, S., et al. (2015). Promiscuous T-cell responses to drugs and drug-haptens. J. Allergy Clin. Immunol. 136:e478. doi: 10.1016/j.jaci.2015.02.036

Young, R., Barker, R., Pile, K., Cookson, W., and Taylor, A. (1995). The association of HLA-DR3 with specific IgE to inhaled acid anhydrides. Am. J. Respir. Crit. Care Med. 151, 219-221. doi: 10.1164/ajrccm.151.1.7812558
Yum, S. K., Kim, T., and Hwang, M. Y. (2014). Polycystic ovaries is a disproportionate signal in pharmacovigilance data mining of second generation antipsychotics. Schizophr. Res. 158, 275-276. doi: 10.1016/j.schres.2014. 06.003

Zeng, T., Long, Y. S., Min, F. L., Liao, W. P., and Shi, Y. W. (2015). Association of HLA-B*1502 allele with lamotrigine-induced Stevens-Johnson syndrome and toxic epidermal necrolysis in han Chinese subjects: a meta-analysis. Int. J. Dermatol. 54, 488-493. doi: 10.1111/ijd.12570

Conflict of Interest Statement: The authors declare that the research was conducted in the absence of any commercial or financial relationships that could be construed as a potential conflict of interest.

Copyright (C) 2016 Böhm and Cascorbi. This is an open-access article distributed under the terms of the Creative Commons Attribution License (CC BY). The use, distribution or reproduction in other forums is permitted, provided the original author(s) or licensor are credited and that the original publication in this journal is cited, in accordance with accepted academic practice. No use, distribution or reproduction is permitted which does not comply with these terms. 